\title{
The glucocorticoid receptor in osteoprogenitors regulates bone mass and marrow fat
}

\author{
Jessica L Pierce', Ke-Hong Ding2, Jianrui Xu², Anuj K Sharma1, Kanglun Yu1', Natalia del Mazo Arbona1, \\ Zuleika Rodríguez-Santos', Paul J Bernard3, Wendy B Bollag1,4,5,6, Maribeth H Johnson², Mark W Hamrick¹,5, \\ Dana L Begun7, Xing-Ming Shi², Carlos M Isales $2,5,8$ and Meghan E McGee-Lawrence ${ }^{1,5}$
}

1Department of Cellular Biology and Anatomy, Medical College of Georgia, Augusta University, Augusta, Georgia, USA

2Department of Neuroscience and Regenerative Medicine, Augusta University, Augusta, Georgia, USA

${ }^{3}$ Pediatric Endocrine Specialists of Georgia, Duluth, Georgia, USA

${ }^{4}$ Department of Physiology, Augusta University, Augusta, Georgia, USA

${ }^{5}$ Department of Orthopaedic Surgery, Augusta University, Augusta, Georgia, USA

${ }^{6}$ Charlie Norwood VA Medical Center, Augusta, Georgia, USA

7Department of Orthopaedic Surgery, Mayo Clinic, Rochester, Minnesota, USA

${ }^{8}$ Division of Endocrinology, Diabetes and Metabolism, Department of Medicine, Augusta University, Augusta, Georgia, USA

Correspondence should be addressed to M E McGee-Lawrence: mmcgeelawrence@augusta.edu

\begin{abstract}
Excess fat within bone marrow is associated with lower bone density. Metabolic stressors such as chronic caloric restriction (CR) can exacerbate marrow adiposity, and increased glucocorticoid signaling and adrenergic signaling are implicated in this phenotype. The current study tested the role of glucocorticoid signaling in CR-induced stress by conditionally deleting the glucocorticoid receptor ( $\mathrm{Nr} 3 \mathrm{C}$ ) ; hereafter abbreviated as GR) in bone marrow osteoprogenitors (Osx1-Cre) of mice subjected to CR and ad libitum diets. Conditional knockout of the GR (GR-CKO) reduced cortical and trabecular bone mass as compared to WT mice under both ad libitum feeding and CR conditions. No interaction was detected between genotype and diet, suggesting that the GR is not required for CR-induced skeletal changes. The lower bone mass in GR-CKO mice, and the further decrease in bone by $C R$, resulted from suppressed bone formation. Interestingly, treatment with the $\beta$-adrenergic receptor antagonist propranolol mildly but selectively improved metrics of cortical bone mass in GR-CKO mice during CR, suggesting interaction between adrenergic and glucocorticoid signaling pathways that affects cortical bone. GR-CKO mice dramatically increased marrow fat under both ad libitum and CR-fed conditions, and surprisingly propranolol treatment was unable to rescue CR-induced marrow fat in either WT or GR-CKO mice. Additionally, serum corticosterone levels were selectively elevated in GR-CKO mice with CR, suggesting the possibility of bone-hypothalamus-pituitary-adrenal crosstalk during metabolic stress. This work highlights the complexities of glucocorticoid and $\beta$-adrenergic signaling in stress-induced changes in bone mass, and the importance of GR function in suppressing marrow adipogenesis while maintaining healthy bone mass.
\end{abstract}
Key Words
- skeleton
- marrow adiposity
- osteoprogenitor
- osteoblast
- nutrition
- metabolic stress
- corticosterone
- sympathetic tone
- $\beta$-adrenergic 


\section{Introduction}

The bone marrow niche houses stem cell populations that give rise to blood, immune, bone and fat cells within the skeletal microenvironment. The fate of bone marrow progenitor cells can be influenced by hormones and nutrient signals from the circulation, establishing a relationship between whole-body physiology and bone health (Li et al. 2016). A vital component of the bone marrow microenvironment is the bone marrow stromal cell (BMSC), which is a multipotent progenitor capable of differentiating into osteogenic and adipogenic cell populations within bone (Baker et al. 2015). The differentiation fate of the BMSCs can be influenced by genetic predispositions, dietary and lifestyle factors, stress and injury responses and epigenetics. Osteoblastogenesis is influenced by pathways including Wnt/ $\beta$-catenin, transforming growth factor- $\beta$ (TGF- $\beta$ ), bone morphogenetic proteins (BMPs) and glucocorticoid signaling, among others (Day et al. 2005, Bennett et al. 2007, Kang et al. 2007, Zhang et al. 2012). There is a delicate balance between these mechanisms, and interruptions to the homeostasis of the bone marrow microenvironment can dramatically shift BMSC differentiation patterns at the expense of tissue function and bone health.

Recent studies have uncovered an intricate relationship between caloric intake and bone. For example, chronic caloric deficit induces high bone marrow adipogenesis accompanied by osteopenia in humans and mice (Devlin et al. 2010, Fazeli et al. 2013, Periyasamy-Thandavan et al. 2015, Singhal \& Bredella 2019). It has also been reported that a low-calorie diet reduces bone mass in part by decreasing cortical bone mass while largely sparing trabecular bone in mice (Hamrick et al. 2008). There is evidence that the phenotype produced by caloric restriction (CR) is mediated in part by glucocorticoid signaling (Cawthorn et al. 2016). The metabolic stress of CR can stimulate counter-regulatory hormone secretion, including glucocorticoids, that may interfere with osteoblast function and drive marrow adipose tissue expansion (Devlin et al. 2010, Cawthorn et al. 2016). The enzyme 11ß-hydroxysteroid dehydrogenase type 1 (Hsd11b1) (which converts inactive glucocorticoids to their active forms in the periphery) also mediates upregulated glucocorticoid metabolism throughout the body and locally within bone as a result of CR (Tomlinson et al. 2004, Gathercole et al. 2013). Additionally, it has been reported that in vitro pharmacological inhibition of Hsd11b1 activity protects osteoblasts from glucocorticoidinduced cellular dysfunction (Wu et al. 2013).
These data suggest a potential role for aberrant glucocorticoid signaling in the CR-induced bone phenotype, but the mechanistic role of modulators downstream of Hsd11b1 remain largely unknown.

Activated glucocorticoids bind the glucocorticoid receptor (GR; also known as Nr3c1) within target tissues and drive downstream stress response signaling cascades (Almeida et al. 2011). Once bound to glucocorticoids, the GR translocates to the nucleus to bind glucocorticoid response elements (Nixon et al. 2013, Lim et al. 2015) or associate with transcription factors that act on genomic regulatory elements (Hua et al. 2016a,b). While physiological levels of endogenous glucocorticoids are necessary for osteoblastogenesis and bone formation (Zhou et al. 2013), an excess of circulating glucocorticoids can compromise bone mass by inhibiting osteoblast differentiation and inducing osteoblast and osteocyte apoptosis (Weinstein et al. 1998, O'Brien et al. 2004, Rauch et al. 2010, Weinstein 2012). Downstream glucocorticoid signaling may also drive marrow adipogenesis, as it has been reported that glucocorticoids induce adipocyte commitment and contribute to the fatty infiltration of soft tissues (e.g., liver and skeletal muscle) as well as bone (Canalis et al. 2004, Kuo et al. 2013, Hamrick et al. 2016, Papanastasiou et al. 2017). These findings further support a role for the GR in mediating the bone loss and increased marrow fat caused by CR and suggest that the GR is a key in the response of bone to this facet of metabolic stress.

Sympathetic tone may also be involved in glucocorticoid-induced marrow adiposity (Elefteriou 2005). Osteoblasts express $\beta$-adrenergic receptors ( $\beta$-AR) that, when activated, initiate signaling cascades that result in decreased osteoblast number and activity as well as loss of bone mass. Importantly, the sensitivity of osteoblast to adrenergic signaling is also increased by glucocorticoid treatment (Bonnet et al. 2008, Ma et al. 2011). $\beta$-Adrenergic receptor activity also stimulates adipogenesis and mediates CR-induced marrow adiposity, whereas treatment with the $\beta$-adrenergic antagonist propranolol in a chronic caloric restriction model partially rescues the trabecular bone loss and marrow fat phenotype in mice and rats (Baek \& Bloomfield 2012, Baek et al. 2014b). Moreover, propranolol protects against the loss of bone mass associated with a high-calorie diet (Baek et al. 2014a). Despite these findings, there is still a knowledge gap regarding the functional role of the GR in bone marrow lipid storage in the CR model when $\beta$-blockade occurs.

The current study sought to test the role of the GR in caloric restriction-induced changes in bone and marrow 
fat. Within this model, we also sought to deduce the effect of sympathetic tone on the phenotype of metabolically stressed GR-insufficient bone through the use of the $\beta$-blocker propranolol.

\section{Materials and methods}

\section{Animals and diet administration}

All experiments followed NIH guidelines and were approved by the Institutional Animal Care and Use Committee at Augusta University. As described previously, GR was inactivated through Cre recombinase (Cre)mediated excision of exons $1 \mathrm{C}$ and 2 of the GR gene (Fig. 1A). This modification deletes $50 \%$ of the mature GR protein, encompassing the translation start site and the tau 1 transactivation domain and has previously been shown to effectively disrupt GR action (Brewer et al. 2003, Kim et al. 2006). Osteoprogenitor-specific inactivation of GR was accomplished through Osx1 promoter-driven Cre expression as described previously (Rodda \& McMahon 2006, McGee-Lawrence et al. 2016) to generate GR conditional knockout mice (GR-CKO; GR ${ }^{\mathrm{fl} / \mathrm{fl}}$ :Osx1-Cre+) and control littermates (GR-WT; GR ${ }^{\mathrm{fl} / \mathrm{fl}}$ :Osx1-Cre-) for this study (n=7-8 mice/group; Fig. 1A). While inclusion of an additional 'Cre+ control' (i.e., GR+/+:Osx1-Cre+ for this study) is preferred for knockout models generated with the Osx1-Cre line, due to the presence of a mild, early skeletal phenotype arising from the Osx1-Cre itself, in pilot studies of 6-month-old male mice, we observed that marrow fat was elevated specifically in $\mathrm{GR}^{\mathrm{fl} / \mathrm{fl}}$ :Osx1-Cre+ mice, whereas there were no differences observed between GRfl/flOsx1-Cre- (i.e., 'Cre- control') mice and GR+/+:Osx1-Cre+ (i.e., 'Cre+ control') mice (Supplementary Methods and Supplementary Fig. 1, see section on supplementary data given at the end of this article). Furthermore, the skeletal phenotype of Osx1-Cre+ control mice is reported to resolve by 12 weeks ( 3 months) of age, and all studies reported here were only initiated at 6 months of age (Davey et al. 2012). Consequently, we focused the current study on GR conditional knockout mice (GR-CKO;

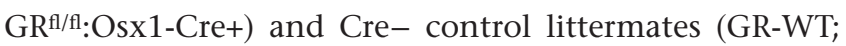

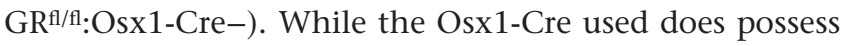
a doxycycline-suppressible Tet-off element, the mice used here were not treated with doxycycline to suppress Cre because studies were initiated after the Osx1-Cre skeletal phenotype was expected to resolve. Consequently, mice used for these studies experienced constitutive expression of Cre in Osx1-expressing cells throughout their development. Female mice were specifically selected for study because in pilot work, we observed similar trends of elevated marrow adiposity in both male and female GR-CKO mice (Supplementary Fig. 1), but trends were much more pronounced in females, reducing the number of animals needed for study. Mice were genotyped by PCR amplification of tail biopsy DNA isolates with appropriate negative and positive controls. Mice were housed in standard rodent cages on a $12 \mathrm{~h}$ light/12 $\mathrm{h}$ darkness schedule. At 6 months of age, female GR-WT and GR-CKO mice were randomly assigned to either ad libitum (AL) or CR feeding for 9 weeks (Fig. 1B). Caloric intake was determined by the average weight of food pellets consumed daily, and CR was defined by a given fraction of the calculated average caloric intake provided to individual AL-fed mice daily. Mice subjected to $\mathrm{CR}$ were provided a $10 \%$ calorie deficit for one week followed by a $25 \%$ calorie deficit for 8 weeks. A subset of CR mice received drinking water with $0.01 \%$ propranolol (PRO, $0.1 \mathrm{mg} / \mathrm{ml}$; Sigma-Aldrich \#P0884) for the duration of the experiment, whereas other mice received only normal water (Vehicle, VEH); drinking water was available to both groups AL. This dosage of propranolol was chosen to match a previous study, where administration of $\sim 0.1 \mathrm{mg} / \mathrm{mL}$ propranolol in the drinking water (equating to a dosage of approximately $6 \mathrm{mg}$ propranolol per $\mathrm{kg}$ body mass) was sufficient to prevent accumulation of bone marrow adipocytes with CR in female rats (Baek \& Bloomfield 2012). Calcein injections (10 mg/kg) were administered at 5 and 2 days before killing for measurements of cortical bone mineralization. Mice were killed via carbon dioxide inhalation and were not fasted the evening prior to killing.

\section{Body composition and bone mineralization}

Whole-body dual energy X-ray absorptiometry (DXA; Kubtec Digimus, KUB Technologies, Milford, CT, USA) was performed on isoflurane-anesthetized mice 2 days before killings. Bone mineral content (BMC) and bone mineral density (BMD) for whole mouse and femur middiaphysis regions of interest were calculated using the manufacturer's software. All DXA analyses excluded heads and ear tags. Percent fat mass was calculated as the fraction of the total body pixels interpreted by the manufacturer's software as fat tissue via densitometry. Final body mass measurements were recorded 5 days before killing. https://joe.bioscientifica.com https://doi.org/10.1530/JOE-19-0230
(C) 2019 Society for Endocrinology Published by Bioscientifica Ltd.
Printed in Great Britain 
A

Glucocorticoid Receptor (GR) Protein:

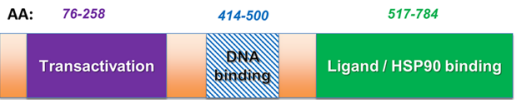

Glucocorticoid Receptor Genomic Locus

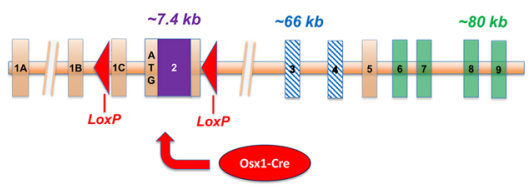

C

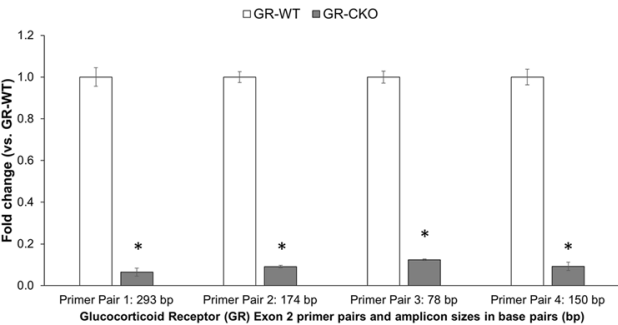

D
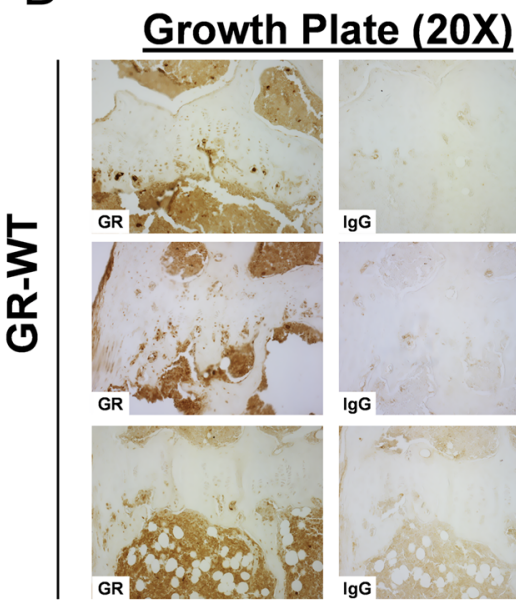

IgG
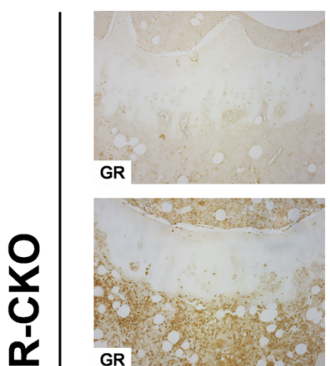

㭊
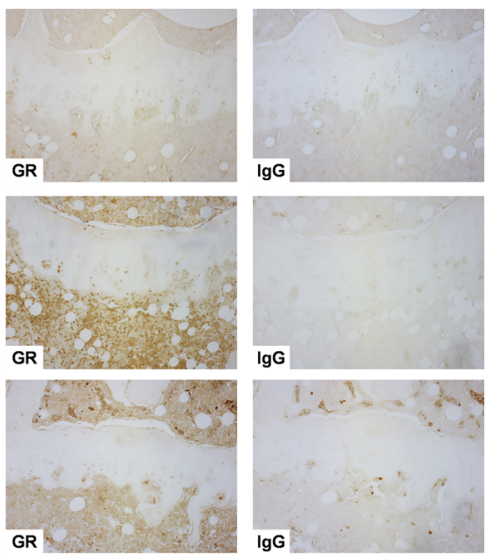

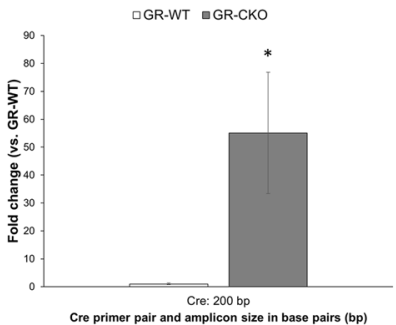

B g-Week Treatment Timeline
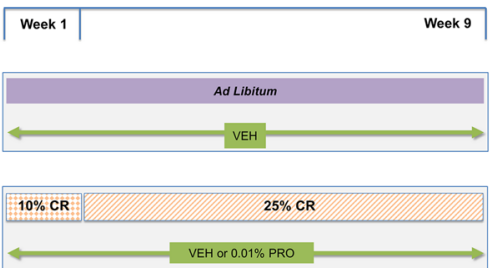

Cre primer pair and amplicon size in base pairs (bp)

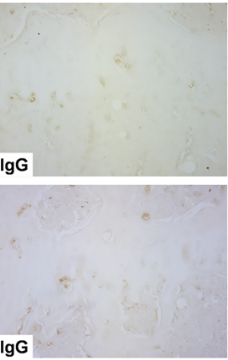

\section{Cortical Bone (40X)}
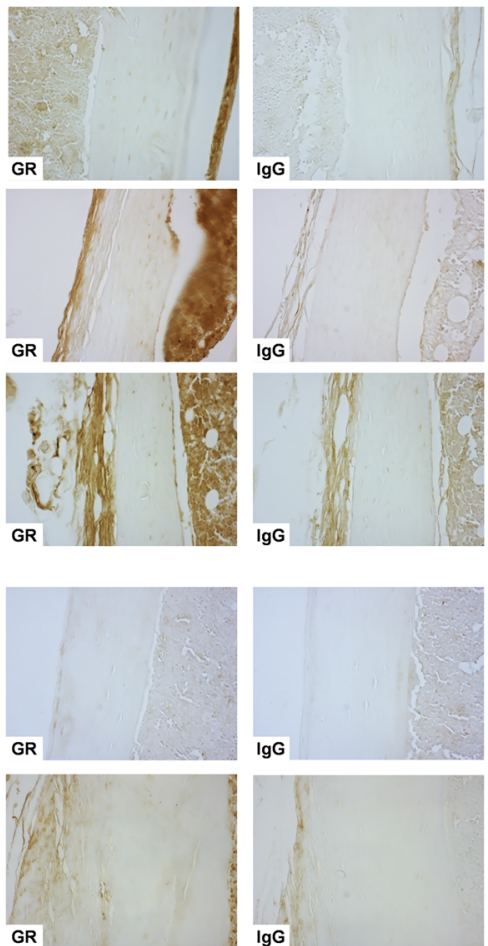

IgG
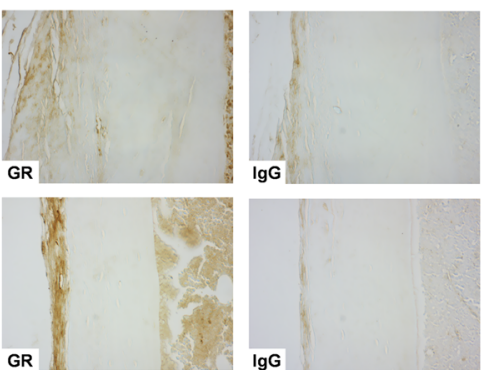

\section{Figure 1}

Confirmation of GR knockdown in GR-CKO mice. (A) Model for glucocorticoid receptor (GR) conditional deletion with Osterix1-Cre (Osx1-Cre) to generate an osteoprogenitor-specific knockout model. (B) Timeline for ad libitum (AL), caloric restriction (CR) and $C R+$ propranolol (PRO) treatment conditions. (C) Expression of GR and Cre RNA was measured by qPCR in BMSC subjected to osteogenic culture for 7 days. $n=4$ biological replicates per group, $* P<0.05$ vs GR-CKO WT for each primer pair. (D) GR protein expression was detected via

immunohistochemistry in the tibia; the inset label on each image indicates which antibody was used (GR, glucocorticoid receptor; IgG, mouse IgG isotype control). GR-CKO mice demonstrated reduced intensity of GR staining in the growth plate and in cortical bone (e.g., osteocytes). Images are representative of staining patterns observed across the entire group for each genotype ( $n=7$ animals per group); each row of images is from a different mouse. Growth plate images were captured with a $20 \times$ objective, whereas cortical bone images were captured with a $40 \times$ objective, as indicated. 
Isolation of murine BMSC, cell culture and analysis of gene expression

Primary murine BMSC from the AL-fed groups were harvested from one femur and two humerii via bone marrow flush with basal medium composed of minimum essential media (MEM)- $\alpha, 20 \%$ fetal bovine serum (Atlanta Biologicals, Flowery Branch, GA, USA), 1\% non-essential amino acids (Gibco \#11140-050), and 1\% antibiotic/ antimycotic (Gibco \#15240-062) as previously described (McGee-Lawrence et al. 2016). BMSC-derived osteoblasts were generated via culture in osteogenic induction medium (basal medium $+50 \mu \mathrm{g} / \mathrm{mL}$ ascorbic acid, $10 \mathrm{mM}$ $\beta$-glycerophosphate and $10^{-7} \mathrm{M}$ dexamethasone), which began at seeding (Day 0) and were maintained under osteogenic conditions until harvest after 7 days in culture. Media changes for all cells in culture were performed every 3 days until harvest. Total RNA was isolated from the cultures in TRIzol (Invitrogen) following the manufacturer's instructions. RNA quality was assessed by absorbance at 260 and $280 \mathrm{~nm}$ (NanoDrop, Thermo Scientific). RNA (1000 ng) was reverse-transcribed from four biological replicates per genotype (where each replicate represented an independent well of a six-well plate) into cDNA using a Superscript III cDNA synthesis kit (Superscript III First Strand synthesis (\#18080-051), Life Technologies) and a programmable thermal cycler (Bio-Rad). Expression levels of mRNA for the GR (official gene name: nuclear receptor subfamily 3, group C; Nr3c1) were quantified by subjecting cDNA to real-time PCR amplification (37.5 ng cDNA per $15 \mu \mathrm{L}$ reaction volume reaction, run in triplicate) using a Bio-Rad CFX Connect system, SYBR green reagent (Quanta Biosciences \#95054-500) and primers designed to bind within the floxed region of the GR Exon 2. Expression levels of Cre mRNA were also assessed as previously described (McGeeLawrence et al. 2013, 2016). Gene expression levels were quantified using the comparative threshold cycle $\left(2^{-\Delta \Delta C t}\right)$ method (McGee-Lawrence et al. 2016). Glyceraldehyde3-phosphate dehydrogenase (GAPDH) was used as the internal control (housekeeping gene) for normalization. Primer sequences are shown in Table 1.

\section{Micro-computed tomography, histology, histomorphometry and immunohistochemistry}

Femora and tibiae were harvested at killing and fixed in $10 \%$ neutral buffered formalin for 24 hours followed by storage in $70 \% \mathrm{EtOH}$. Femora were scanned by microcomputed tomography (microCT, $10.5 \mu \mathrm{m}$ isotropic voxel size; Scanco VivaCT 40) with settings of $70 \mathrm{kV}$ and $300 \mathrm{~ms}$ for analysis of cortical and trabecular bone architecture. The cortical bone region of interest was equal to $5 \%$ of total bone length, with a proximal starting point at $50 \%$ of total bone length. The trabecular bone region of interest was equal to $7 \%$ of total bone length, with a proximal starting point at $82 \%$ of total bone length. Architectural parameters (e.g., cortical bone area, trabecular number and spacing, trabecular volume) were calculated with the manufacturer's software.

Following microCT analysis, femora were embedded in methyl methacrylate (MMA) for microtome sectioning and mounting ( $5 \mu \mathrm{m}$ sections; Leica Biosystems). Calceinlabeled sections were imaged on a fluorescence microscope (20x objective, Olympus IX70; Olympus Life Science) with a digital camera attachment (Qicam; QImaging) for dynamic histomorphometry measurements in the distal femoral metaphyseal trabecular bone with Bioquant Osteo. Mineralizing surface (MS/BS, \%) was quantified as $1 / 2$ single labeled surface+double labeled surface normalized to bone surface. Mineral apposition rate (MAR, $\mu \mathrm{m} /$ day) was quantified as inter-label width divided by time between calcein injections. Bone formation rate (BFR/BS, $\mu \mathrm{m} /$ day) was quantified as the product of MAR and MS/BS. Tibiae were decalcified for 2 weeks in 15\% EDTA followed by paraffin embedding and microtome sectioning. Sections for each tibia were stained with either hematoxylin and eosin (H\&E; Sigma \#HHS16, \#H110316) or a commercially available tartrate-resistant acid phosphatase kit

Table 1 Primer sequences used for PCR analyses of mRNA expression.

\begin{tabular}{l} 
Primer pair name \\
\hline GR primer pair 1 \\
GR primer pair 2 \\
GR primer pair 3 \\
GR primer pair 4 \\
Cre \\
Gapdh
\end{tabular}

\begin{tabular}{l} 
Target/amplicon size \\
\hline GR Exon 2, $293 \mathrm{bp}$ \\
GR Exon 2, $174 \mathrm{bp}$ \\
GR Exon 2, $78 \mathrm{bp}$ \\
GR Exon 2, $150 \mathrm{bp}$ \\
Cre, $200 \mathrm{bp}$ \\
Gapdh, $59 \mathrm{bp}$
\end{tabular}

\begin{tabular}{l}
\hline Forward primer, $\mathbf{5}^{\prime} \mathbf{- 3}$ \\
\hline CTCCCCCTGGTAGAGACGAA \\
GGGGAATGACTTGGGCTACC \\
CTCAATAGGTCGACCAGCCG \\
CATGGCGTGAGTACCTCTGG \\
ACCAGCCAGCTATCAACTCG \\
GGGAAGCCCATCACCATCT
\end{tabular}

Reverse primer, 5'-3

TCCCATGGACAGTGAAACGG AACTCCTTCTCTGTCGGGGT CTTCTCTGTCGGGGTAGCAC TCCAGACCCTTGGCACCTAT TTACATTGGTCCAGCCACC GCCTCACCCCATTTGATGTT

Note that 'GR' refers to the gene $\mathrm{Nr3c1}$, the murine glucocorticoid receptor. 
(TRAP; Sigma-Aldrich \#386A) and mounted using a xylene-based mounting medium. Images were captured with $10 \times(\mathrm{H} \& \mathrm{E})$ and $20 \times(\mathrm{TRAP})$ objectives on a brightfield microscope (Olympus IX70). Bone marrow adiposity was measured from the H\&E-stained sections as adipocyte ghost area normalized to marrow area (Ad.Ar/Ma.Ar, \%) and adipocyte density (N.Ad/Ma.Ar, \#/mm²). Osteoclast number (N.Oc/BS, \#/mm) and osteoclast surface (Oc.S/BS, \%) were quantified from the TRAP-stained sections in the proximal tibia metaphyseal trabecular bone using Bioquant Osteo software. All histological data were collected in a blinded fashion.

Serial sections from the decalcified tibiae were immunohistochemically stained to detect the localization of the GR, using methodology as previously described (McGee-Lawrence et al. 2013, Hagan et al. 2019). Briefly, paraffin sections were deparaffinized in xylene and rehydrated through graded alcohols to water. Tissue sections were heated in a citrate buffer solution for $10 \mathrm{~min}$ for antigen retrieval followed by incubation for $2 \mathrm{~h}$ at room temperature with a GR monoclonal antibody (BuGR2; 1:50 dilution, \#MA1-510, Invitrogen) or mouse IgG isotype control (1:50 dilution, I-2000; Vector Laboratories). The sections were then incubated in chromogens and were detected with a polyvalent secondary HRP kit (Abcam, ab93697) and 3,3'-diaminobenzidine (DAB, 10-min incubation; Sigma-Aldrich, D3939) as per manufacturer's instructions. Images were captured using a microscope (Olympus IX-70) and digital camera (QImaging QICam and QCapture software).

\section{Enzyme-linked immunosorbent assays}

Serum samples were obtained by cardiac puncture at killing followed by centrifugation in serum separator tubes (BD Microtainer \#365967, Franklin Lakes, NJ, USA) and stored at $-80^{\circ} \mathrm{C}$ until analysis. A mouse TRAcP-5b ELISA (MouseTrap ${ }^{\mathrm{TM}}$; \#SB-TR103, Immunodiagnostic Systems, Gaithersburg, MD, USA) was used to measure the circulating bone resorption marker TRAP $5 b$. Additional aliquots of serum were analyzed in a rat/ mouse procollagen I intact N-terminal (P1NP) enzyme immunoassay (\#AC-33F1, Immunodiagnostic Systems) for quantification of bone formation markers. Serum glucocorticoids were measured using a corticosterone ELISA (\#ab108821, Abcam) using a 100-fold dilution of mouse serum and provided protocols. All ELISA plates were measured with a microplate reader (BioTek Synergy HT, Winooski, VT, USA) using Gen5 software and readings at 405 (P1NP) and 450 nm (TRAcP-5b, corticosterone) wavelengths, as recommended for each assay. Serum data were normalized to calibrants and standards provided in respective ELISA kits.

\section{Statistical analyses}

After checking for normality and appropriate distribution, the effects of diet were compared between WT and GR-CKO mice by two-factor ( 2 genotype $\times 2$ diet) analysis of variance (ANOVA) with interaction using JMP Pro 14 statistical software (SAS Institute). The effects of propranolol intervention on the CR diet background were compared between WT and GR-CKO mice with two-factor ANOVA (2 genotype $\times 2$ treatment) with interaction. Histomorphometric measurements of osteoclasts (N.Oc/BS and Oc.S/BS) were rank-transformed prior to analysis to stabilize the variance across groups and to reduce the influence of outliers. For gene expression analyses, GR-WT and GR-CKO groups were compared via $t$-tests. Statistical significance was defined by $95 \%$ confidence $(P<0.05)$. Box plots in figures show median, quartiles and outlier fences for each dataset, where outlier fences represent first quartile -1.5 * (interquartile range) and third quartile +1.5 * (interquartile range).

\section{Results}

\section{Confirmation of GR knockdown in GR ${ }^{\mathrm{fl} / \mathrm{fl}: \text { Osx1-Cre+ mice }}$}

BMSC and skeletal tissue were harvested from the GR-CKO and GR-WT mice on $A L$ diets to assess the efficiency of GR knockdown in the GR-CKO mice. BMSC from the GR-CKO mice subjected to osteogenic culture demonstrated an approximately 90\% knockdown of GR mRNA levels as compared to cells from GR-WT mice (Fig. 1C). These same BMSC cultures expressed high levels of Cre mRNA (+55 fold signal as compared to GR-WT cultures). To confirm these results at the protein level in bone tissue, we performed immunohistochemistry against the GR. These studies demonstrated robust knockdown of the GR in Osx1-Cre-targeted regions including the pre-hypertrophic chondrocytes and osteo-lineage cells (Fig. 1D). These studies confirmed that the GR-CKO mice were deficient in skeletal expression of the glucocorticoid receptor.

\section{GR deletion in Osx-expressing cells reduced bone mass under $A L$ and $C R$ feeding conditions}

GR-WT and GR-CKO mice were subjected to AL or CR feeding conditions for 9 weeks. Body mass was reduced 
by both GR deficiency $(-10.6 \%, P=0.0002)$ and by caloric restriction $(-17.6 \%, P<0.0001)$, but there was not a significant interaction between these factors $(P=0.453)$, meaning that $\mathrm{CR}$ decreased body mass similarly in GR-WT and GR-CKO mice (Fig. 2A). Percent fat mass was not different between groups (data not shown; $P>0.203$ ), perhaps because female mice resist loss of fat mass during CR (Shi et al. 2007, Li et al. 2010b, Cawthorn et al. 2016). While no differences were observed in whole-body BMD or BMC between groups ( $P>0.516$, data not shown), both genotype and CR diet administration negatively impacted cortical bone mineralization in the femur as measured by DXA (Fig. 2B-D). Specifically, femur BMD and BMC were reduced by GR deficiency $(-5.3$ and $-7.6 \%$ respectively;
$P<0.004)$ and by CR $(-10.4$ and $-13.9 \%$ respectively, $P<0.0001)$ with no interaction effect $(P>0.535$, Fig. $2 \mathrm{C}$ and D). Cortical bone geometry was similarly affected; for example, cortical bone thickness was reduced in GR-CKO mice $(-7.6 \%, P=0.0001)$ and by CR $(-15.9 \%, P<0.0001)$, but no interaction effects were observed $(P>0.736$; Fig. $2 \mathrm{E}$ and Table 2). Taken together, these data support the idea that both GR deficiency and caloric restriction are deleterious for cortical bone, but CR effects are not exacerbated in GR-CKO mice.

With regards to trabecular bone, although trabecular bone volume fraction was not different between groups $(P>0.130)$, subtle but statistically significant differences were observed in the trabecular bone properties Tb.N and

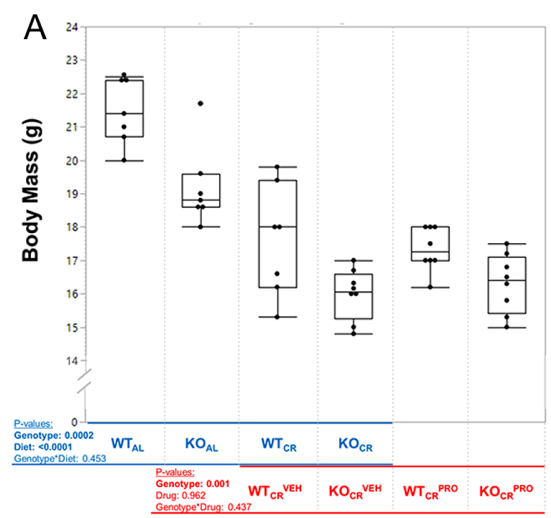

B
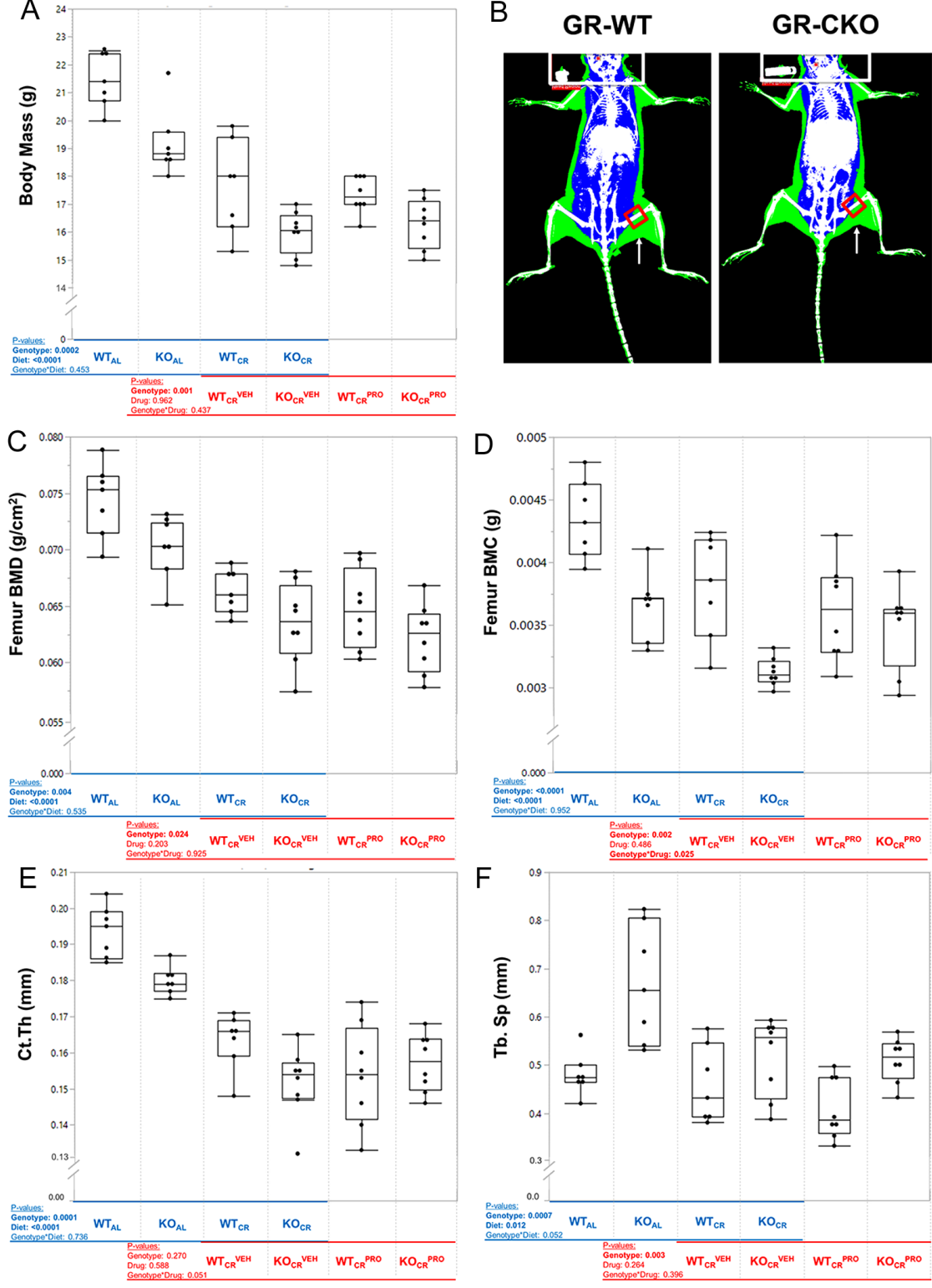
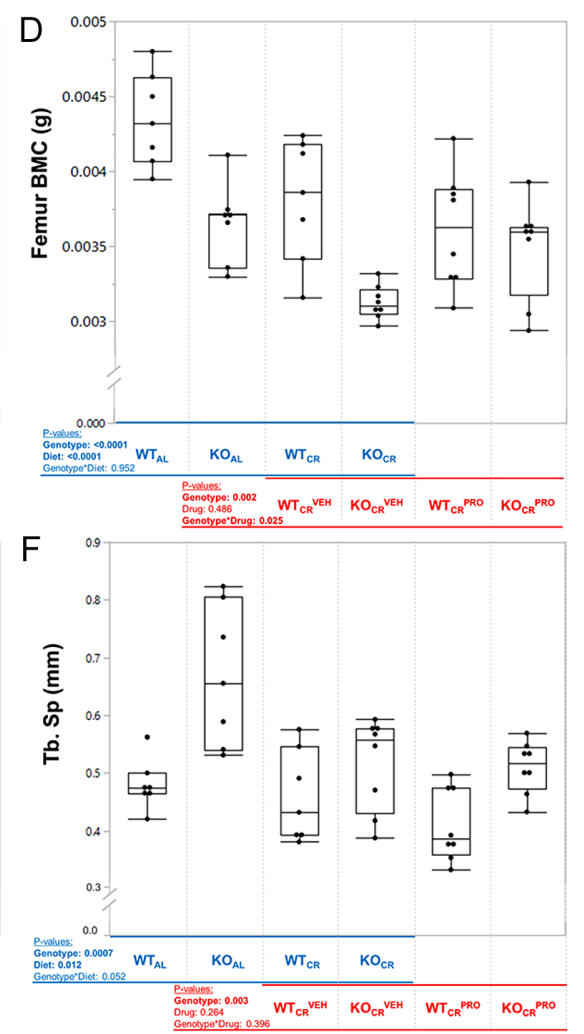

\section{Figure 2}

GR-CKO mice are smaller and have less bone mass than GR-WT mice. (A) Body mass of animals at the conclusion of study ( $n=7$ to 8 per group) and $(B)$ representative images of body composition dual X-ray absorptiometry scans for GR-WT and GR-CKO mice (white = bone mass, blue $=$ lean mass, green $=$ fat mass). Larger white boxes on representative images outline area of exclusion from analysis. Smaller red boxes outline area of analysis for (C) femur bone mineral density (BMD) and (D) femur bone mineral content (BMC). Micro-computed tomography analyses for femur (E) cortical bone thickness and (F) trabecular bone separation are shown quantitatively. Boxes show median, quartiles and outlier fences for each dataset. Each data point represents one mouse. Statistical analyses for comparing the influence of diet (blue text) and propranolol intervention (red text) between GR-WT and GR-CKO mice are shown beneath each graph. 


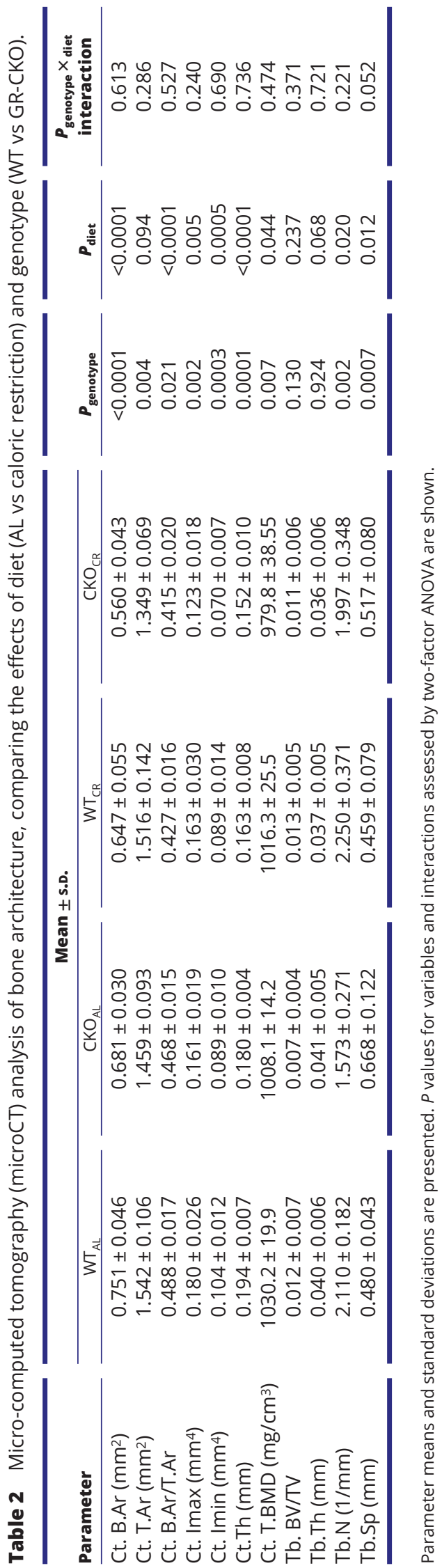

https://joe.bioscientifica.com https://doi.org/10.1530/JOE-19-0230 (c) 2019 Society for Endocrinology Published by Bioscientifica Ltd.
Printed in Great Britain
Tb.Sp between groups. Trabecular number was decreased by GR deficiency $(-17.5 \%, P=0.002)$ and increased by CR $(+14.9 \%, P=0.020)$, whereas trabecular separation was increased by GR-deficiency $(+25.2 \%, P=0.0007)$ but decreased by CR $(-14.7 \%, P=0.012)$ (Fig. $2 F)$. Taken together, these data suggest that loss of GR in Osxexpressing cells is mildly detrimental for trabecular bone, but CR minimally impacts trabecular bone properties, as previously reported (Hamrick et al. 2008).

\section{Propranolol treatment differentially affected cortical bone mass in GR-WT and GR-CKO mice subjected to $C R$}

Propranolol treatment had little to no impact on body mass, whole-body DXA measurements, and trabecular bone in the calorically restricted GR-WT and GR-CKO mice, except for stimulating a mild decrease in trabecular bone thickness $(-11.2 \%, P=0.023)$ that was comparable between GR-WT and GR-CKO mice (Fig. 1C, F and Table 3). In cortical bone, however, interaction effects between genotype and drug administration were observed for several properties including cortical bone moment of inertia, cortical bone area and femur BMC (Fig. 1E, F, G and Table 3). These data suggest that propranolol treatment differentially affected cortical bone in the calorically restricted GR-WT and GR-CKO mice, with a mild detrimental effect on cortical bone in GR-WT mice but a mild stimulatory effect on cortical bone mass in GR-CKO mice.

\section{Bone formation was impaired by CR and GR-CKO in vivo}

To determine how bone remodeling activity contributed to the skeletal phenotypes observed with GR-CKO and CR, ELISAs were performed on sera isolated from the mice to quantify markers of bone formation and resorption. Circulating markers were verified in a site-specific fashion through histomorphometric measurements of metaphyseal trabecular bone in the proximal tibia (TRAP staining) and distal femur (calcein measurements). Bone formation activity was suppressed by both GR deficiency and by $\mathrm{CR}$, as seen by changes in serum P1NP levels ( -41.3 in GR-CKO vs GR-WT, $-42.8 \%$ in GR vs $\mathrm{AL}$ ) and trabecular bone dynamic histomorphometry (Fig. 3A, B, $C$ and $D)$. No interaction effects were observed, suggesting that CR suppressed bone formation similarly between GR-WT and GR-CKO mice $(P>0.184)$. Histomorphometric measurements of trabecular bone osteoclasts suggested a 


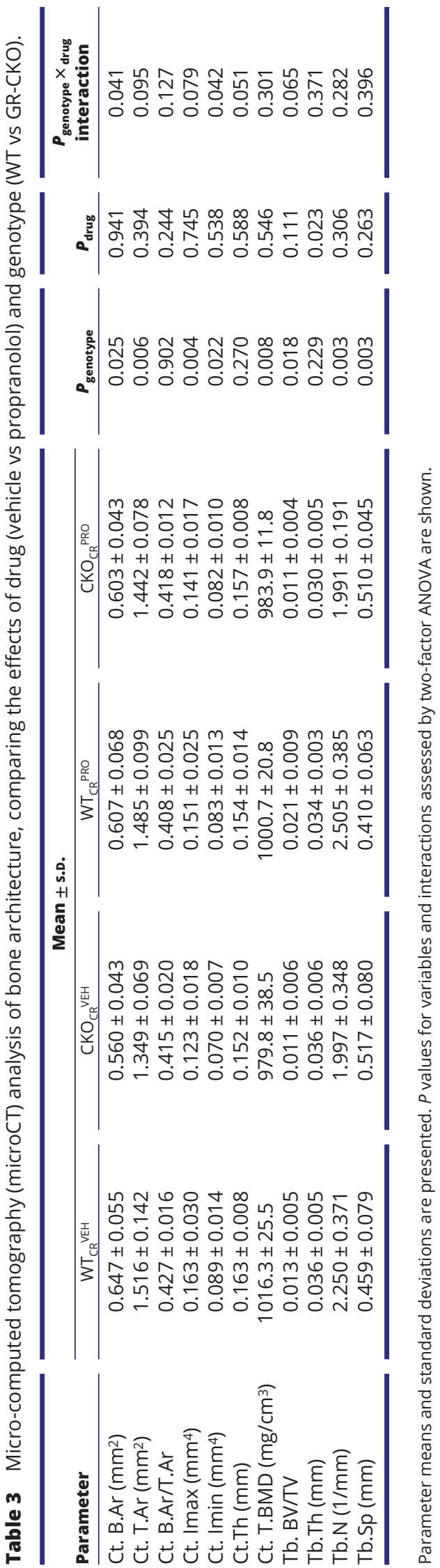

https://joe.bioscientifica.com https://doi.org/10.1530/JOE-19-0230
(C) 2019 Society for Endocrinology Published by Bioscientifica Ltd. similar pattern of decreased bone resorption with both GR deficiency and CR, with no interaction effects (Fig. 3E, F and G). In contrast, serum TRAcP5b levels, which serve as a circulating marker of osteoclast number throughout the entire body (Halleen et al. 2002, Alatalo et al. 2003), were suppressed by GR-deficiency ( $-41.0 \%$ in GR-CKO vs GR-WT, $P=0.006$ ) but were not impacted by $\mathrm{CR}$ in this study (Fig. 3H). Taken together, these data support the assertion that the reduced bone mass observed with GR insufficiency and with CR could be attributed to decreased bone formation activity, rather than high levels of bone resorption. Propranolol treatment had little impact on bone remodeling activity, except for a mild suppression of serum P1NP levels that was similar between genotypes $(-24.5 \%, P=0.014$; Fig. 3).

\section{GR-insufficient mice accumulated more marrow fat than GR-WT mice in vivo}

Previous work demonstrated that chronic caloric restriction-induced marrow fat accumulation in WT mice and that $\beta$-blockade with propranolol partially rescued this CR-induced marrow fat phenotype (Devlin et al. 2010, Baek et al. 2014b, Periyasamy-Thandavan et al. 2015, Cawthorn et al. 2016). To determine whether the GR is a mechanistic factor in caloric restriction-induced marrow adiposity in vivo, marrow adipogenesis was measured histologically in long bones harvested from the mice. Interestingly, these studies demonstrated that GR deficiency in osteoprogenitors drove an increase in marrow adiposity, as both marrow adipocyte density and area fraction were greater in GR-CKO as compared to GR-WT mice $(+169 \%$ adipocyte density, $+139 \%$ marrow adipocyte fraction, $P<0.003$; Fig. 4$)$. To the best of our knowledge, this phenotype has not been previously reported in mechanistic investigations of the role of the GR in bone biology (Liu et al. 2016). Consistent with previous studies, CR was also observed to drive an increase in marrow adiposity ( $+96 \%$ adipocyte density, $+396 \%$ marrow adipocyte fraction, $P<0.003$; Fig. 4$)$. No interaction effects were observed between genotype and diet, suggesting that the GR is not required for CR-induced marrow adipogenesis. Interestingly, although propranolol was previously reported to ameliorate bone marrow adiposity induced by CR (Baek \& Bloomfield 2012, Baek et al. 2014b), we observed no effect of propranolol on marrow adiposity in our studies even in WT mice $(P>0.591$, Fig. 4). These data suggest that $\beta$-adrenergic signaling might not always be a critical component of CR-induced marrow adipogenesis. 

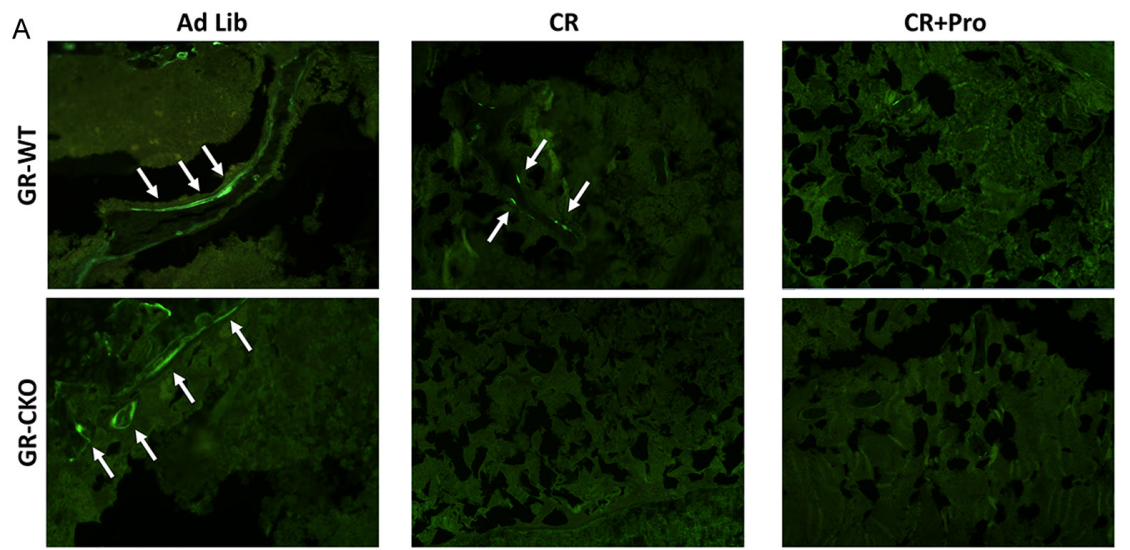

B

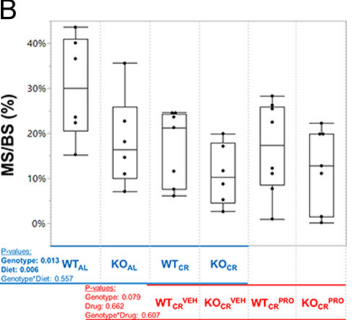

$\mathrm{C}_{w}$
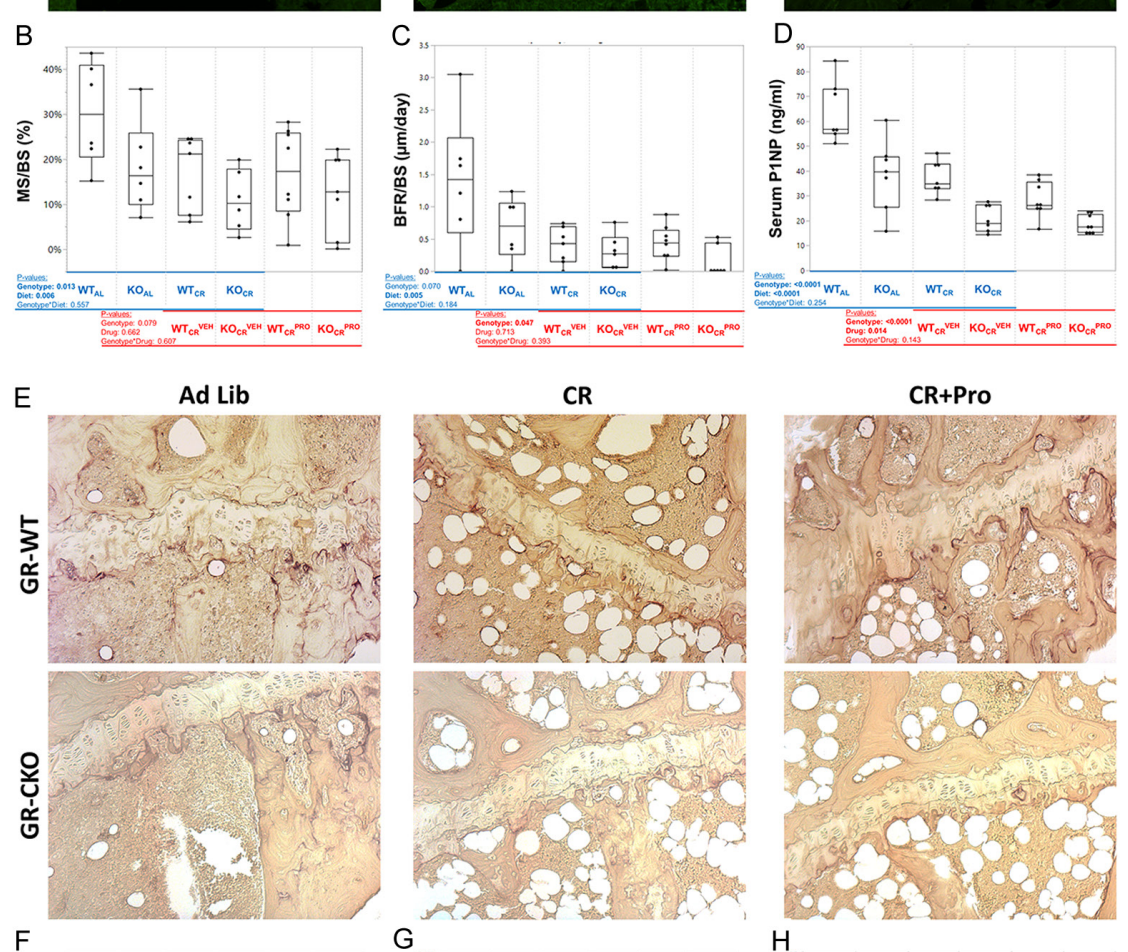

$\mathrm{F}$
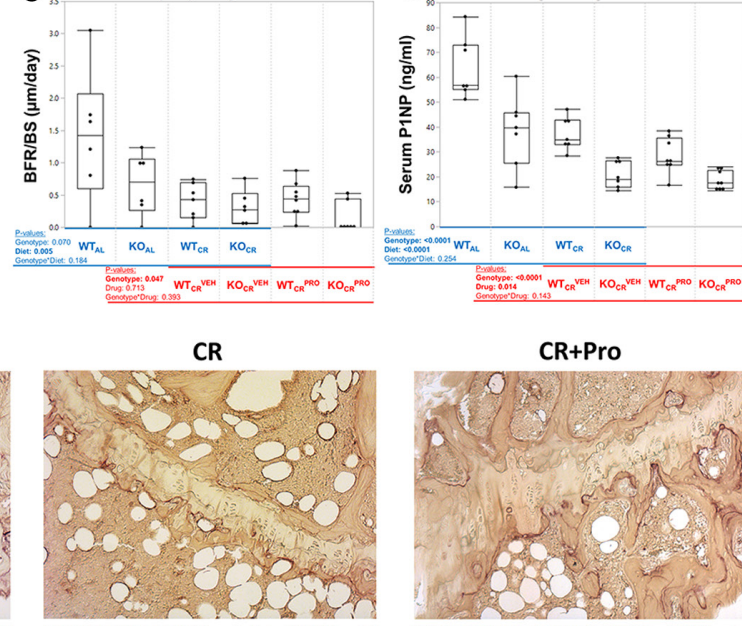

Figure 3

GR conditional deletion and caloric restriction suppress bone remodeling. (A) Representative images of calcein-labeled bone surface from each group. Arrows in representative images highlight areas of active mineralization (original magnification: 10× objective). (B) Mineralizing surface (MS/BS) and (C) bone formation rate (BFR/BS) for each condition. (D) Serum levels of procollagen type I $\mathrm{N}$-terminal (P1NP, ng/mL), a circulating marker of bone formation activity. (E) Representative images of tartrate-resistant acid phosphatase (TRAP) staining on tibiae (original magnification: 20× objective).

(F) Quantification of TRAP-positive osteoclast surface and (G) osteoclast number (N.Oc)
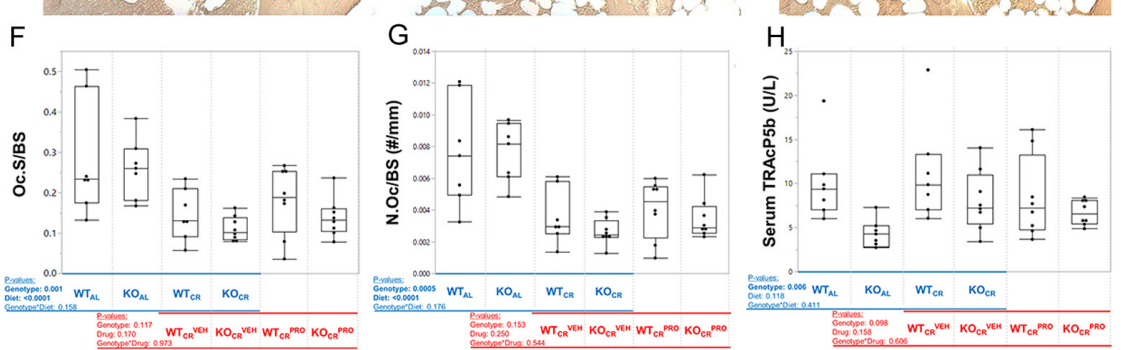
normalized to trabecular bone surface. (H) ELISA measurement of serum concentrations of TRACP-5b, a circulating marker of osteoclast number. Boxes on each graph show median, quartiles and outlier fences for each dataset. Each data point represents one mouse. Statistical analyses for comparing the influence of diet (blue text) and propranolol intervention (red text) between GR-WT and GR-CKO mice are shown beneath each graph.

\section{GR-CKO mice have high serum glucocorticoids under} $C R$, which is rescued by propranolol treatment

A canonical physiological response to metabolic stressors such as CR is the upregulated secretion of glucocorticoids - such as corticosterone in mice - from the adrenal cortex into the circulation (Chapman et al. 2013, Cawthorn et al. 2016, Teich et al. 2016). To determine the glucocorticoid response of GR-WT and GR-CKO mice in response to
$\mathrm{CR}$ and propranolol treatment, serum samples from the mice were analyzed by a corticosterone ELISA. Under AL conditions, there were negligible differences in circulating corticosterone between GR-WT and GR-CKO mice (Fig. 5). Surprisingly, CR differentially impacted corticosterone levels in the serum between GR-CKO and GR-WT mice, significantly increasing circulating corticosterone only in the GR-CKO animals (genotypex diet interaction $P$ value $=0.012$; Fig. 5). Propranolol treatment differentially 

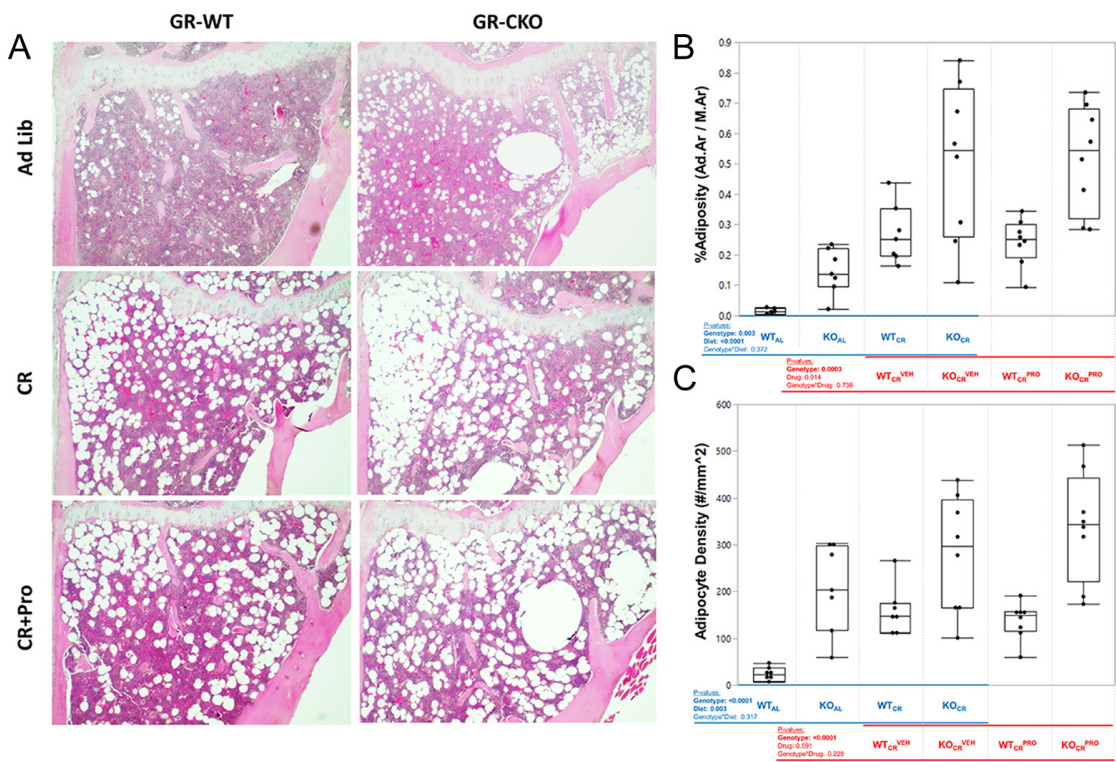
Figure 4
GR-CKO mice have more marrow fat than GR-WT mice. (A) Representative H\&E-stained tibiae (original magnification: 20× objective) showing 'adipose ghosts' indicative of marrow fat. (B) Adipocyte area fraction (Ad.Ar/Ma.Ar) and (C) adipocyte density (\# adipocytes per $\mathrm{mm}^{2}$ marrow area) were quantified for each sample. Boxes show median, quartiles and outlier fences for each dataset. Each data point represents one mouse. Statistical analyses for comparing the influence of diet (blue text) and propranolol intervention (red text) between GR-WT and GR-CKO mice are shown beneath each graph.

affected corticosterone levels in GR-WT and GR-CKO mice during $\mathrm{CR}$, suppressing corticosterone levels in GR-CKO mice while having no impact on GR-WT mice (genotype $\times$ drug interaction $P$ value $=0.001$; Fig. 5). Together, these data suggest an aberrant stress response of GR-insufficient animals to $\mathrm{CR}$ that is sensitive to $\beta$-blockade, and a potential role for bone-specific GR activity in regulating whole-body glucocorticoid signaling.

\section{Discussion}

Chronic CR interrupts the metabolic homeostasis of bone. Glucocorticoid signaling, which is upregulated by stress and inflammation, is implicated in decreasing bone mass and mediating fat accumulation in the marrow. The current study sought to test the role of glucocorticoids in CR-induced marrow adipogenesis and bone turnover through conditional deletion of the glucocorticoid receptor in osteoprogenitors, revealing that loss of GR function in osteoprogenitors reduced bone mass and impaired bone formation as measured by histomorphometry and serum P1NP levels. The low bone mass phenotype of the GR-insufficient animals highlights the importance of physiological levels of glucocorticoid signaling and GR function for proper osteogenesis. Our results suggest that sympathetic tone has complex roles in bone maintenance during CR. Propranolol-treated GR-CKO mice were slightly better protected against the CR-induced loss of femur cortical bone than WT littermates, but showed no such improvement in trabecular bone mass. It is plausible that CR-induced cortical bone loss is promoted by activation of the $\beta 2 \mathrm{AR}$, which can be upregulated by circulating glucocorticoids and leptin (Ma et al. 2011, Baek \& Bloomfield 2012). Further work is needed to better understand these stress response mechanisms in bone.

The GR-CKO model used in this study conditionally deleted the transactivation domain of the GR in Osterix1-expressing osteoprogenitor cells, rendering the

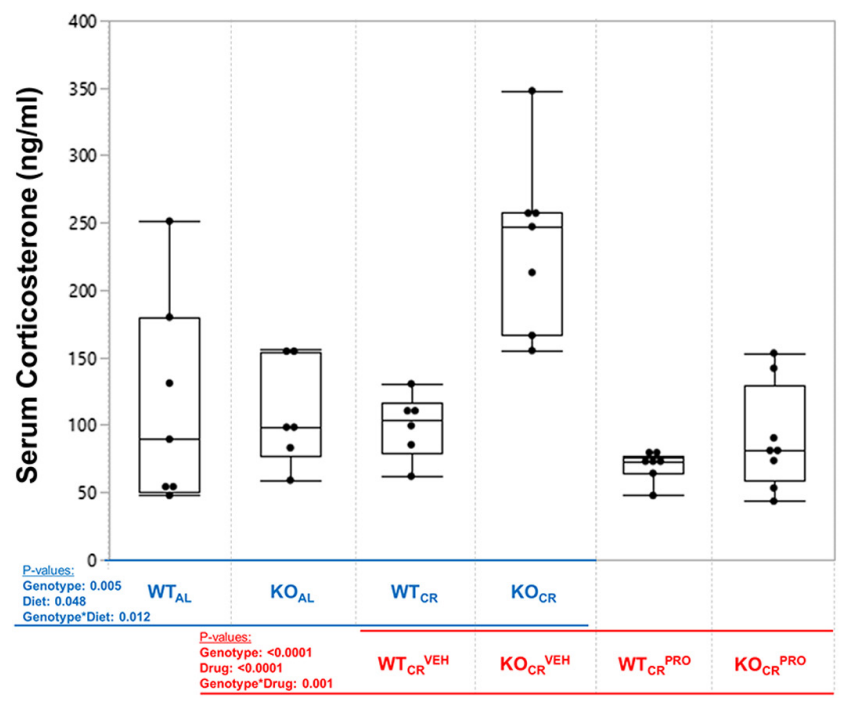

\section{Figure 5}

Circulating corticosterone levels are elevated by GR-CKO and caloric restriction. ELISA measurement at the conclusion of the study of the active glucocorticoid corticosterone $(\mathrm{ng} / \mathrm{mL})$ in serum harvested from GR-WT and GR-CKO mice subjected to AL, CR or CR+Prop treatment conditions. Boxes show median, quartiles and outlier fences for each dataset. Each data point represents one mouse. Statistical analyses for comparing the influence of diet (blue text) and propranolol intervention (red text) between GR-WT and GR-CKO mice are shown beneath the graph. 
GR inactive through dimerization but not completely deleted by Cre-LoxP recombination. Previous work using a Runx2-Cre-mediated GR conditional deletion model confirmed that the monomeric GR is still functional and can attenuate osteoblast function when activated (Rauch et al. 2010). Moreover, the monomeric GR induces genetic transrepression via downstream genomic elements - described as negative glucocorticoid response elements (nGREs) - and the recruitment of mediating transcription factors such as AP-1, NF- $\mathrm{kB}$ and nuclear receptor corepressors 1 and 2 (NCoR1 and SMRT) (Hudson et al. 2013, Oakley \& Cidlowski 2013, Lim et al. 2015). As an example, there is evidence that activation of an nGRE upstream of a Runx2-binding site on the osteocalcin promoter is a mechanism by which glucocorticoids can repress the Egr2/Krox20 enhancer that is required for osteoblast function and trabecular bone formation (Leclerc et al. 2005). A GR dimerization mutation in mice also showed that the monomeric GR can inhibit bone resorption by downregulating retinoic acid receptordependent RANKL production (Conaway et al. 2011). These findings raise the possibility that the upregulated serum corticosterone resulting from $\mathrm{CR}$ in GR-CKO animals could act via the monomeric GR to induce bone loss through impaired osteogenesis rather than increased resorption. Additional work will be necessary to determine the activity of the GR in our model and its potential interaction with transcription factors and genomic elements during metabolic stress responses. Moreover, whether this mechanism contributes to CR-induced marrow adiposity in GR-CKO mice remains in question.

We were surprised to observe that a caloric restrictioninduced increase in bone marrow adiposity was not prevented by propranolol administration in either GR-WT or GR-CKO mice. This may be due in part to the dosage of propranolol used to modulate sympathetic tone in this study. We selected a dose of $0.1 \mathrm{mg} / \mathrm{mL}$ propranolol administered in drinking water based on a previous study demonstrating efficacy of this dosage in limiting marrow adipogenesis during CR (Baek \& Bloomfield 2012). However, we recognize that several other investigations into the role of sympathetic tone in regulation of bone and marrow adiposity have used higher dosages of approximately $0.5 \mathrm{mg} / \mathrm{mL}$ propranolol in drinking water (Takeda et al. 2002, Motyl et al. 2013, Baek et al. 2014a,b). Accordingly, the limited impact of propranolol on bone and marrow fat in the current study may have been due to incomplete blockade of adrenergic signaling. However, it is important to note that propranolol administration did induce several biological changes in the current study, including blunting the upregulation of serum corticosterone in GR-CKO mice subjected to CR (Fig. 5) and inducing a mild decrease in both circulating P1NP levels and trabecular bone thickness similarly between genotypes (Fig. 3D and Table 3). Based on our data, we hypothesize that $\beta$-adrenergic signaling might not always be a critical component of CR-induced marrow adipogenesis, but further studies are needed to thoroughly test this hypothesis.

Loss of GR function in the murine CR model presented here was not protective against excess marrow adipogenesis. Recent work in rats demonstrated that treatment with the GR antagonist mifepristone was protective against adiposity rebound in rats following the completion of chronic exercise and CR conditions (Teich et al. 2016). In this study, however, GR conditional deletion did not protect against CR-driven marrow fat, and instead resulted in a high marrow fat phenotype even under AL feeding conditions. This is somewhat surprising, as recent work suggested that the GR augments adipose tissue formation, as GR-deficient mouse embryonic fibroblasts were impaired in their ability to form adipocytes both in vitro and in vivo (Bauerle et al. 2018). Our results suggest alternative mechanisms by which marrow fat accumulates in this osteoprogenitorspecific GR-deficient model. One possibility is that systemic rather than local glucocorticoids in the GR-CKO mice bind the GR to drive its activation of the master adipogenic transcription factor, peroxisome proliferatoractivated receptor $\gamma$ (PPAR $\gamma$ ), via known interactions of the GR with PPAR $\gamma$-transcription regulating CCAAT/ enhancer-binging proteins (C/EBPs) (Grontved et al. 2013, Li et al. 2013, Zhao et al. 2013). However, little is known regarding whether the monomeric GR interacts with C/EBPs or the potential for C/EBP-mediated transrepression (rather than activation) to stimulate BMSC-derived adipogenesis. Another possibility is that the binding and activation of the mineralocorticoid receptor (MR) is involved in the phenotype, as corticosterone also binds this receptor (Li et al. 2005); indeed, MR has high affinity for glucocorticoids and in the absence of the inactivating enzyme, 11ß-hydroxysteroid dehydrogenase- 2 may be occupied by these steroids. Moreover, the MR has implications in facilitating adipogenesis, and adipocytespecific MR activity is associated with metabolic syndrome and glucocorticoid-induced lipid accumulation (Hirata et al. 2009, Hoppmann et al. 2010, Caprio et al. 2011, Nguyen Dinh Cat et al. 2016). These findings also highlight a potential limitation to the GR conditional deletion model used in the current study, as Osx1-Cre fate mapping 
studies have confirmed expression of this Cre reporter in bone marrow adipocytes (Liu et al. 2013); therefore, at present, it is not possible to discriminate between whether the enhanced adiposity in the GR-CKO mice is a progenitor-driven effect or an adipocyte-driven effect. However, it is important to note that several studies have addressed the role of the GR in adiponectin-expressing adipocytes, and bone marrow adipocytes are an important source of adiponectin during CR (Cawthorn et al. 2014). Interestingly, the majority of these reports suggest that GR deletion in adipocytes does not independently promote adipocyte expansion or hypertrophy (Bose $\mathrm{et} \mathrm{al}$. 2016, Desarzens \& Faresse 2016, Shen et al. 2017) and may even decrease fat mass (Mueller et al. 2017). Thus, if the primary effect of Osx1-Cre on marrow adiposity resulted from directly targeting bone marrow adipocytes, it would be logical to expect that marrow fat should be unaffected or decreased in GR-CKO animals. In contrast, the current study found robust increases in marrow adiposity in the GR-CKO animals under both AL and CR feeding conditions. A remaining question is the role of glucocorticoid-activated MR in BMSC-derived osteoblasts and adipocytes - including the role of MR-driven marrow adipogenesis and mechanistic interactions of the GR and MR in BMSC. With both of these possible mechanisms, however, it is important to note that we only observed an increase in circulating corticosterone levels in the GR-CKO mice under conditions of CR. As we only measured serum corticosterone at the time of killing, and glucocorticoids demonstrate substantial circadian variation in their circulating levels (Halberg et al. 1959, Gong et al. 2015), it is possible that we may have missed the optimal time point at which to compare corticosterone levels across different groups. In future studies, it will be important to conduct a thorough time course of blood sampling to observe how circulating GC levels are impacted by loss of GR in the skeleton throughout periods of activity and dormancy.

It is also important to consider the complex role of $\beta$-adrenergic signaling in marrow adipogenesis, as it has been demonstrated that $\beta-\mathrm{AR}$ antagonism with propranolol can positively regulate BMSC adipogenesis as well as C/EBP and PPAR $\gamma$ expression, while the $\beta$-AR agonist isoproterenol inhibits these processes ( $\mathrm{Li}$ et al. $2010 a$ ). As previously mentioned, however, $\beta$-adrenergic signaling during CR shows differing roles in terms of facilitating bone loss and marrow fat accumulation (Baek \& Bloomfield 2012, Baek et al. 2014b). It was also recently reported that marrow adipose tissue has a blunted response to adrenergic signaling as compared to other fat depots like white adipose tissue (Scheller et al. 2019). This further demonstrates the complexities of inflammatory and stress responses in bone-resident cell types and the potential for canonical signaling pathways to be pro- or anti-adipogenic depending on mechanistic crosstalk that is yet to be elucidated in the CR stress model.

While the findings in this study highlight the complex effects of glucocorticoid signaling and GR activity in bone during CR, there are limitations to acknowledge in the study design that, when addressed in future work, may further clarify mechanisms of interest. For instance, the presented work was completed in only in female mice; this was done because pilot studies suggested similar trends of increased marrow fat accumulation in both male and female GR-CKO mice as compared to WT controls, but trends were more pronounced in females. We consequently focused on females for further study, but this observation raises the question of whether sex differences exist in the response of marrow adiposity to loss of GR-mediated signaling and CR in bone. In addition, as described earlier, it is important to acknowledge that the preferred control for the Osx1-Cre, $\mathrm{GR}^{+/+}$:Osx1-Cre+ mice (i.e., 'Cre+ WT' mice), was not included here. In pilot studies, presented in the Supplementary Methods, we observed no difference in marrow adiposity between Cre- and Cre+ WT animals, but, these pilot data were from male mice at 6 months of age, whereas mice in the dietary studies presented here were female mice that were 6 months old at the onset of studies and 8 months old at killing. It will be important to age- and sex-match additional control groups in future studies of Osx1-Cre: GR-CKO animals in order to draw better conclusions regarding the role of the GR in regulation of bone mass and marrow fat during periods of metabolic stress. Lastly, while we confirmed appreciable reduction in GR expression in bone via immunostaining and in marrowderived osteoblasts from these mice, we did not perform a comprehensive evaluation of GR expression in potential off-target tissues, such as the brain, that may express both GR and Osterix (Park et al. 2011, Madalena \& Lerch 2017). From our immunostaining analyses, we note that the intensity of GR staining in the general bone marrow area tended to be reduced in the GR-CKO mice, although the impact of this observation on outcome measurements in the current study is not clear. Interpretation of data in the Osx1-Cre: GR-CKO model described here could be strengthened by analyses of GR expression in the whole bone marrow stroma and brain to conclusively establish whether observed effects are mediated directly by loss of GR in bone or influenced via off-target effects in other 
tissues. Our future work will address the aforementioned limitations in methodology to better understand the role of the GR in the skeletal response to stressors.

In conclusion, the present study suggests that GR function in osteoprogenitors is necessary to maintain bone mass and inhibit marrow fat accumulation that occurs with the stress of long-term CR. The $\beta$-blocker propranolol selectively improved cortical bone mass in GR-CKO mice but had no impact on CR-induced marrow adiposity in either GR-WT or GR-CKO animals. Future work will focus on elucidating the molecular mechanisms driving the osteoporotic phenotype of GR-insufficient bone as well as determining how loss of the GR in osteoprogenitors affects the response of bone to common physiological stressors such as aging.

\section{Supplementary data}

This is linked to the online version of the paper at https://doi.org/10.1530/ JOE-19-0230.

\section{Declaration of interest}

The authors declare that there is no conflict of interest that could be perceived as prejudicing the impartiality of the research reported.

\section{Funding}

This work was supported by the National Institutes on Aging (grant number P01-AG036675; Project 4) and the American Diabetes Association (grant number 1-16-JDF-062). The contents do not represent the views of the U.S. Department of Veterans Affairs or the United States Government.

\section{Acknowledgements}

The authors would like to acknowledge Dr Louis Muglia for providing the GR-floxed mouse model.

\section{References}

Alatalo SL, Peng Z, Janckila AJ, Kaija H, Vihko P, Vaananen HK \& Halleen JM 2003 A novel immunoassay for the determination of tartrate-resistant acid phospatase $5 \mathrm{~b}$ from rat serum. Journal of Bone and Mineral Research 18 134-139. (https://doi.org/10.1359/ jbmr.2003.18.1.134)

Almeida M, Han L, Ambrogini E, Weinstein RS \& Manolagas SC 2011 Glucocorticoids and tumor necrosis factor alpha increase oxidative stress and suppress Wnt protein signaling in osteoblasts. Journal of Biological Chemistry 286 44326-44335. (https://doi.org/10.1074/jbc. M111.283481)

Baek K \& Bloomfield SA 2012 Blocking beta-adrenergic signaling attenuates reductions in circulating leptin, cancellous bone mass, and marrow adiposity seen with dietary energy restriction. Journal of Applied Physiology 113 1792-1801. (https://doi.org/10.1152/ japplphysiol.00187.2012)

Baek K, Hwang HR, Park HJ, Kwon A, Qadir AS \& Baek JH 2014a Propranolol, a $\beta$-adrenergic antagonist, attenuates the decrease in trabecular bone mass in high calorie diet fed growing mice. $B M B$ Reports 47 506-511. (https://doi.org/10.5483/bmbrep.2014.47.9.265)

Baek K, Park HJ, Hwang HR \& Baek JH 2014b Propranolol attenuates calorie restriction- and high calorie diet-induced bone marrow adiposity. BMB Reports 47 587-592. (https://doi.org/10.5483/ bmbrep.2014.47.10.176)

Baker N, Boyette LB \& Tuan RS 2015 Characterization of bone marrowderived mesenchymal stem cells in aging. Bone $7037-47$. (https://doi. org/10.1016/j.bone.2014.10.014)

Bauerle KT, Hutson I, Scheller EL \& Harris CA 2018 Glucocorticoid receptor signaling is not required for in vivo adipogenesis. Endocrinology 159 2050-2061. (https://doi.org/10.1210/en.201800118)

Bennett CN, Ouyang H, Ma YL, Zeng Q, Gerin I, Sousa KM, Lane TF Krishnan V, Hankenson KD \& MacDougald OA 2007 Wnt10b increases postnatal bone formation by enhancing osteoblast differentiation. Journal of Bone and Mineral Research 22 1924-1932. (https://doi.org/10.1359/jbmr.070810)

Bonnet N, Pierroz DD \& Ferrari SL 2008 Adrenergic control of bone remodeling and its implications for the treatment of osteoporosis. Journal of Musculoskeletal and Neuronal Interactions 8 94-104.

Bose SK, Hutson I \& Harris CA 2016 Hepatic glucocorticoid receptor plays a greater role than adipose GR in metabolic syndrome despite renal compensation. Endocrinology 157 4943-4960. (https://doi. org/10.1210/en.2016-1615)

Brewer JA, Khor B, Vogt SK, Muglia LM, Fujiwara H, Haegele KE, Sleckman BP \& Muglia LJ 2003 T-cell glucocorticoid receptor is required to suppress COX-2-mediated lethal immune activation. Nature Medicine 9 1318-1322. (https://doi.org/10.1038/nm895)

Canalis E, Bilezikian JP, Angeli A \& Giustina A 2004 Perspectives on glucocorticoid-induced osteoporosis. Bone 34 593-598. (https://doi. org/10.1016/j.bone.2003.11.026)

Caprio M, Antelmi A, Chetrite G, Muscat A, Mammi C, Marzolla V Fabbri A, Zennaro MC \& Fève B 2011 Antiadipogenic effects of the mineralocorticoid receptor antagonist drospirenone: potential implications for the treatment of metabolic syndrome. Endocrinology 152 113-125. (https://doi.org/10.1210/en.2010-0674)

Cawthorn WP, Scheller EL, Learman BS, Parlee SD, Simon BR, Mori H, Ning X, Bree AJ, Schell B, Broome DT, et al. 2014 Bone marrow adipose tissue is an endocrine organ that contributes to increased circulating adiponectin during caloric restriction. Cell Metabolism 20 368-375. (https://doi.org/10.1016/j.cmet.2014.06.003)

Cawthorn WP, Scheller EL, Parlee SD, Pham HA, Learman BS, Redshaw CM, Sulston RJ, Burr AA, Das AK, Simon BR, et al. 2016 Expansion of bone marrow adipose tissue during caloric restriction is associated with increased circulating glucocorticoids and not with hypoleptinemia. Endocrinology 157 508-521. (https://doi.org/10.1210/ en.2015-1477)

Chapman KE, Coutinho AE, Zhang Z, Kipari T, Savill JS \& Seckl JR 2013 Changing glucocorticoid action: 11beta-hydroxysteroid dehydrogenase type 1 in acute and chronic inflammation. Journal of Steroid Biochemistry and Molecular Biology 137 82-92. (https://doi. org/10.1016/j.jsbmb.2013.02.002)

Conaway HH, Pirhayati A, Persson E, Pettersson U, Svensson O, Lindholm C, Henning P, Tuckermann J \& Lerner UH 2011 Retinoids stimulate periosteal bone resorption by enhancing the protein RANKL, a response inhibited by monomeric glucocorticoid receptor. Journal of Biological Chemistry 286 31425-31436. (https://doi. org/10.1074/jbc.M111.247734)

Davey RA, Clarke MV, Sastra S, Skinner JP, Chiang C, Anderson PH \& Zajac JD 2012 Decreased body weight in young Osterix-Cre transgenic mice results in delayed cortical bone expansion and accrual. https://joe.bioscientifica.com https://doi.org/10.1530/JOE-19-0230 (c) 2019 Society for Endocrinology Published by Bioscientifica Ltd. Printed in Great Britain 
Transgenic Research 21 885-893. (https://doi.org/10.1007/s11248-0119581-z)

Day TF, Guo X, Garrett-Beal L \& Yang Y 2005 Wnt/beta-catenin signaling in mesenchymal progenitors controls osteoblast and chondrocyte differentiation during vertebrate skeletogenesis. Developmental Cell 8 739-750. (https://doi.org/10.1016/j.devcel.2005.03.016)

Desarzens S \& Faresse N 2016 Adipocyte glucocorticoid receptor has a minor contribution in adipose tissue growth. Journal of Endocrinology 230 1-11. (https://doi.org/10.1530/JOE-16-0121)

Devlin MJ, Cloutier AM, Thomas NA, Panus DA, Lotinun S, Pinz I, Baron R, Rosen CJ \& Bouxsein ML 2010 Caloric restriction leads to high marrow adiposity and low bone mass in growing mice. Journal of Bone and Mineral Research 25 2078-2088. (https://doi.org/10.1002/jbmr.82)

Elefteriou F 2005 Neuronal signaling and the regulation of bone remodeling. Cellular and Molecular Life Sciences 62 2339-2349. (https://doi.org/10.1007/s00018-005-5175-3)

Fazeli PK, Horowitz MC, Macdougald OA, Scheller EL, Rodeheffer MS, Rosen CJ \& Klibanski A 2013 Marrow fat and bone - new perspectives. Journal of Clinical Endocrinology and Metabolism 98 935-945. (https:// doi.org/10.1210/jc.2012-3634)

Gathercole LL, Lavery GG, Morgan SA, Cooper MS, Sinclair AJ, Tomlinson JW \& Stewart PM 2013 11beta-Hydroxysteroid dehydrogenase 1: translational and therapeutic aspects. Endocrine Reviews 34 525-555. (https://doi.org/10.1210/er.2012-1050)

Gong S, Miao YL, Jiao GZ, Sun MJ, Li H, Lin J, Luo MJ \& Tan JH 2015 Dynamics and correlation of serum cortisol and corticosterone under different physiological or stressful conditions in mice. PLOS ONE 10 e0117503. (https://doi.org/10.1371/journal.pone.0117503)

Grontved L, John S, Baek S, Liu Y, Buckley JR, Vinson C, Aguilera G \& Hager GL 2013 C/EBP maintains chromatin accessibility in liver and facilitates glucocorticoid receptor recruitment to steroid response elements. EMBO Journal 32 1568-1583. (https://doi.org/10.1038/ emboj.2013.106)

Hagan ML, Bahraini A, Pierce JL, Bass SM, Yu K, Elsayed R, Elsalanty M, Johnson MH, McNeil A, McNeil PL, et al. 2019 Inhibition of osteocyte membrane repair activity via dietary vitamin e deprivation impairs osteocyte survival. Calcified Tissue International 104 224-234. (https:// doi.org/10.1007/s00223-018-0487-0)

Halberg F, Albrecht PG \& Bittner JJ 1959 Corticosterone rhythm of mouse adrenal in relation to serum corticosterone and sampling. American Journal of Physiology 197 1083-1085. (https://doi.org/10.1152/ ajplegacy.1959.197.5.1083)

Halleen JM, Ylipahkala H, Alatalo SL, Janckila AJ, Heikkinen JE, Suominen H, Cheng S \& Vaananen HK 2002 Serum tartrate-resistant acid phosphatase $5 \mathrm{~b}$, but not $5 \mathrm{a}$, correlates with other markers of bone turnover and bone mineral density. Calcified Tissue International 71 20-25. (https://doi.org/10.1007/s00223-001-2122-7)

Hamrick MW, Ding KH, Ponnala S, Ferrari SL \& Isales CM 2008 Caloric restriction decreases cortical bone mass but spares trabecular bone in the mouse skeleton: implications for the regulation of bone mass by body weight. Journal of Bone and Mineral Research 23 870-878. (https://doi.org/10.1359/jbmr.080213)

Hamrick MW, McGee-Lawrence ME \& Frechette DM 2016 Fatty infiltration of skeletal muscle: mechanisms and comparisons with bone marrow adiposity. Frontiers in Endocrinology 7 69. (https://doi. org/10.3389/fendo.2016.00069)

Hirata A, Maeda N, Hiuge A, Hibuse T, Fujita K, Okada T, Kihara S, Funahashi T \& Shimomura I 2009 Blockade of mineralocorticoid receptor reverses adipocyte dysfunction and insulin resistance in obese mice. Cardiovascular Research 84 164-172. (https://doi. org/10.1093/cvr/cvp191)

Hoppmann J, Perwitz N, Meier B, Fasshauer M, Hadaschik D, Lehnert H \& Klein J 2010 The balance between gluco- and mineralo-corticoid action critically determines inflammatory adipocyte responses. Journal of Endocrinology 204 153-164. (https://doi.org/10.1677/JOE-09-0292)
Hua G, Ganti KP \& Chambon P 2016a Glucocorticoid-induced tethered transrepression requires SUMOylation of GR and formation of a SUMO-SMRT/NCoR1-HDAC3 repressing complex. PNAS 113 E635-E643. (https://doi.org/10.1073/pnas.1522826113)

Hua G, Paulen L \& Chambon P $2016 b$ GR SUMOylation and formation of an SUMO-SMRT/NCoR1-HDAC3 repressing complex is mandatory for GC-induced ir nGRE-mediated transrepression. PNAS 113 E626-E634. (https://doi.org/10.1073/pnas.1522821113)

Hudson WH, Youn C \& Ortlund EA 2013 The structural basis of direct glucocorticoid-mediated transrepression. Nature Structural and Molecular Biology 20 53-58. (https://doi.org/10.1038/nsmb.2456)

Kang S, Bennett CN, Gerin I, Rapp LA, Hankenson KD \& Macdougald OA 2007 Wnt signaling stimulates osteoblastogenesis of mesenchymal precursors by suppressing CCAAT/enhancer-binding protein alpha and peroxisome proliferator-activated receptor gamma. Journal of Biological Chemistry 282 14515-14524. (https://doi.org/10.1074/jbc. M700030200)

Kim HJ, Zhao H, Kitaura H, Bhattacharyya S, Brewer JA, Muglia LJ, Ross FP \& Teitelbaum SL 2006 Glucocorticoids suppress bone formation via the osteoclast. Journal of Clinical Investigation $\mathbf{1 1 6}$ 2152-2160. (https://doi.org/10.1172/JCI28084)

Kuo T, Harris CA \& Wang JC 2013 Metabolic functions of glucocorticoid receptor in skeletal muscle. Molecular and Cellular Endocrinology 380 79-88. (https://doi.org/10.1016/j.mce.2013.03.003)

Leclerc N, Noh T, Khokhar A, Smith E \& Frenkel B 2005 Glucocorticoids inhibit osteocalcin transcription in osteoblasts by suppressing Egr2/ Krox20-binding enhancer. Arthritis and Rheumatism 52 929-939. (https://doi.org/10.1002/art.20872)

Li Y, Suino K, Daugherty J \& Xu HE 2005 Structural and biochemical mechanisms for the specificity of hormone binding and coactivator assembly by mineralocorticoid receptor. Molecular Cell 19 367-380. (https://doi.org/10.1016/j.molcel.2005.06.026)

Li H, Fong C, Chen Y, Cai G \& Yang M 2010a Beta-adrenergic signals regulate adipogenesis of mouse mesenchymal stem cells via cAMP/ PKA pathway. Molecular and Cellular Endocrinology 323 201-207. (https://doi.org/10.1016/j.mce.2010.03.021)

Li X, Cope MB, Johnson MS, Smith DL. \& Nagy TR 2010b Mild calorie restriction induces fat accumulation in female $\mathrm{C} 57 \mathrm{BL} / 6 \mathrm{~J}$ mice. Obesity 18 456-462. (https://doi.org/10.1038/oby.2009.312)

Li J, Zhang N, Huang X, Xu J, Fernandes JC, Dai K \& Zhang X 2013 Dexamethasone shifts bone marrow stromal cells from osteoblasts to adipocytes by C/EBPalpha promoter methylation. Cell Death and Disease 4 e832. (https://doi.org/10.1038/cddis.2013.348)

Li J, Liu X, Zuo B \& Zhang L 2016 The role of bone marrow microenvironment in governing the balance between osteoblastogenesis and adipogenesis. Aging and Disease 7 514-525. (https://doi.org/10.14336/AD.2015.1206)

Lim HW, Uhlenhaut NH, Rauch A, Weiner J, Hubner S, Hubner N, Won KJ, Lazar MA, Tuckermann J \& Steger DJ 2015 Genomic redistribution of GR monomers and dimers mediates transcriptional response to exogenous glucocorticoid in vivo. Genome Research $\mathbf{2 5}$ 836-844. (https://doi.org/10.1101/gr.188581.114)

Liu Y, Strecker S, Wang L, Kronenberg MS, Wang W, Rowe DW \& Maye P 2013 Osterix-cre labeled progenitor cells contribute to the formation and maintenance of the bone marrow stroma. PLOS ONE 8 e71318. (https://doi.org/10.1371/journal.pone.0071318)

Liu P, Baumgart M, Groth M, Wittmann J, Jack HM, Platzer M, Tuckermann JP \& Baschant U 2016 Dicer ablation in osteoblasts by Runx2 driven cre-loxP recombination affects bone integrity, but not glucocorticoid-induced suppression of bone formation. Scientific Reports 6 32112. (https://doi.org/10.1038/srep32112)

Ma Y, Nyman JS, Tao H, Moss HH, Yang X \& Elefteriou F 2011 beta2Adrenergic receptor signaling in osteoblasts contributes to the catabolic effect of glucocorticoids on bone. Endocrinology $\mathbf{1 5 2}$ 1412-1422. (https://doi.org/10.1210/en.2010-0881) https://joe.bioscientifica.com https://doi.org/10.1530/JOE-19-0230 (c) 2019 Society for Endocrinology Published by Bioscientifica Ltd. Printed in Great Britain 
Madalena KM \& Lerch JK 2017 The effect of glucocorticoid and glucocorticoid receptor interactions on brain, spinal cord, and glial cell plasticity. Neural Plasticity 2017 8640970. (https://doi. org $/ 10.1155 / 2017 / 8640970)$

McGee-Lawrence ME, Bradley EW, Dudakovic A, Carlson SW, Ryan ZC, Kumar R, Dadsetan M, Yaszemski MJ, Chen Q, An KN, et al. 2013 Histone deacetylase 3 is required for maintenance of bone mass during aging. Bone 52 296-307. (https://doi.org/10.1016/j. bone.2012.10.015)

McGee-Lawrence ME, Carpio LR, Schulze RJ, Pierce JL, McNiven MA, Farr JN, Khosla S, Oursler MJ \& Westendorf JJ 2016 Hdac3 deficiency increases marrow adiposity and induces lipid storage and glucocorticoid metabolism in osteochondroprogenitor cells. Journal of Bone and Mineral Research 31 116-128. (https://doi.org/10.1002/ jbmr.2602)

Motyl KJ, Bishop KA, Demambro VE, Bornstein SA, Le P, Kawai M, Lotinun S, Horowitz MC, Baron R, Bouxsein ML, et al. 2013 Altered thermogenesis and impaired bone remodeling in Misty mice. Journal of Bone and Mineral Research 28 1885-1897. (https://doi.org/10.1002/ jbmr.1943)

Mueller KM, Hartmann K, Kaltenecker D, Vettorazzi S, Bauer M, Mauser L, Amann S, Jall S, Fischer K, Esterbauer H, et al. 2017 Adipocyte glucocorticoid receptor deficiency attenuates aging- and HFD-induced obesity and impairs the feeding-fasting transition. Diabetes $\mathbf{6 6}$ 272-286. (https://doi.org/10.2337/db16-0381)

Nguyen Dinh Cat A, Antunes TT, Callera GE, Sanchez A, Tsiropoulou S, Dulak-Lis MG, Anagnostopoulou A, He Y, Montezano AC, Jaisser F, et al. 2016 Adipocyte-specific mineralocorticoid receptor overexpression in mice is associated with metabolic syndrome and vascular dysfunction: role of redox-sensitive PKG-1 and Rho kinase. Diabetes 65 2392-2403. (https://doi.org/10.2337/db15-1627)

Nixon M, Andrew R \& Chapman KE 2013 It takes two to tango: dimerisation of glucocorticoid receptor and its anti-inflammatory functions. Steroids 78 59-68. (https://doi.org/10.1016/j. steroids.2012.09.013)

Oakley RH \& Cidlowski JA 2013 The biology of the glucocorticoid receptor: new signaling mechanisms in health and disease. Journal of Allergy and Clinical Immunology 132 1033-1044. (https://doi. org/10.1016/j.jaci.2013.09.007)

O'Brien CA, Jia D, Plotkin LI, Bellido T, Powers CC, Stewart SA, Manolagas SC \& Weinstein RS 2004 Glucocorticoids act directly on osteoblasts and osteocytes to induce their apoptosis and reduce bone formation and strength. Endocrinology 145 1835-1841. (https://doi. org/10.1210/en.2003-0990)

Papanastasiou L, Fountoulakis S \& Vatalas IA 2017 Adrenal disorders and non-alcoholic fatty liver disease. Minerva Endocrinologica 42 151-163. (https://doi.org/10.23736/S0391-1977.16.02583-9)

Park JS, Baek WY, Kim YH \& Kim JE 2011 In vivo expression of Osterix in mature granule cells of adult mouse olfactory bulb. Biochemical and Biophysical Research Communications 407 842-847. (https://doi. org/10.1016/j.bbrc.2011.03.129)

Periyasamy-Thandavan S, Herberg S, Arounleut P, Upadhyay S, Dukes A, Davis C, Johnson M, McGee-Lawrence M, Hamrick MW, Isales CM, et al. 2015 Caloric restriction and the adipokine leptin alter the SDF-1 signaling axis in bone marrow and in bone marrow derived mesenchymal stem cells. Molecular and Cellular Endocrinology 410 64-72. (https://doi.org/10.1016/j.mce.2015.03.001)

Rauch A, Seitz S, Baschant U, Schilling AF, Illing A, Stride B, Kirilov M, Mandic V, Takacz A, Schmidt-Ullrich R, et al. 2010 Glucocorticoids suppress bone formation by attenuating osteoblast differentiation via the monomeric glucocorticoid receptor. Cell Metabolism 11 517-531. (https://doi.org/10.1016/j.cmet.2010.05.005)

Rodda SJ \& McMahon AP 2006 Distinct roles for Hedgehog and canonical Wnt signaling in specification, differentiation and maintenance of osteoblast progenitors. Development 133 3231-3244. (https://doi. org/10.1242/dev.02480)

Scheller EL, Khandaker S, Learman BS, Cawthorn WP, Anderson LM, Pham HA, Robles H, Wang Z, Li Z, Parlee SD, et al. 2019 Bone marrow adipocytes resist lipolysis and remodeling in response to betaadrenergic stimulation. Bone 118 32-41. (https://doi.org/10.1016/j. bone.2018.01.016)

Shen Y, Roh HC, Kumari M \& Rosen ED 2017 Adipocyte glucocorticoid receptor is important in lipolysis and insulin resistance due to exogenous steroids, but not insulin resistance caused by high fat feeding. Molecular Metabolism 6 1150-1160. (https://doi. org/10.1016/j.molmet.2017.06.013)

Shi H, Strader AD, Woods SC \& Seeley RJ 2007 Sexually dimorphic responses to fat loss after caloric restriction or surgical lipectomy. American Journal of Physiology: Endocrinology and Metabolism 293 E316-E326. (https://doi.org/10.1152/ajpendo.00710.2006)

Singhal V \& Bredella MA 2019 Marrow adipose tissue imaging in humans. Bone 118 69-76. (https://doi.org/10.1016/j.bone.2018.01.009)

Takeda S, Elefteriou F, Levasseur R, Liu X, Zhao L, Parker KL, Armstrong D, Ducy P \& Karsenty G 2002 Leptin regulates bone formation via the sympathetic nervous system. Cell 111 305-317. (https://doi.org/10.1016/s0092-8674(02)01049-8)

Teich T, Dunford EC, Porras DP, Pivovarov JA, Beaudry JL, Hunt $\mathrm{H}_{4}$ Belanoff JK \& Riddell MC 2016 Glucocorticoid antagonism limits adiposity rebound and glucose intolerance in young male rats following the cessation of daily exercise and caloric restriction. American Journal of Physiology: Endocrinology and Metabolism 311 E56-E68. (https://doi.org/10.1152/ajpendo.00490.2015)

Tomlinson JW, Walker EA, Bujalska IJ, Draper N, Lavery GG, Cooper MS, Hewison M \& Stewart PM 2004 11beta-Hydroxysteroid dehydrogenase type 1: a tissue-specific regulator of glucocorticoid response. Endocrine Reviews 25 831-866. (https://doi.org/10.1210/er.2003-0031)

Weinstein RS 2012 Glucocorticoid-induced osteonecrosis. Endocrine 41 183-190. (https://doi.org/10.1007/s12020-011-9580-0)

Weinstein RS, Jilka RL, Parfitt AM \& Manolagas SC 1998 Inhibition of osteoblastogenesis and promotion of apoptosis of osteoblasts and osteocytes by glucocorticoids. Potential mechanisms of their deleterious effects on bone. Journal of Clinical Investigation 102 274-282. (https://doi.org/10.1172/JCI2799)

Wu L, Qi H, Zhong Y, Lv S, Yu J, Liu J, Wang L, Bi J, Kong X, Di W, et al. 2013 11ß-Hydroxysteroid dehydrogenase type 1 selective inhibitor BVT.2733 protects osteoblasts against endogenous glucocorticoid induced dysfunction. Endocrine Journal 60 1047-1058. (https://doi. org/10.1507/endocri.EJ12-0376)

Zhang Y, Khan D, Delling J \& Tobiasch E 2012 Mechanisms underlying the osteo- and adipo-differentiation of human mesenchymal stem cells. Scientific World Journal 2012 793823. (https://doi. org/10.1100/2012/793823)

Zhao QH, Wang SG, Liu SX, Li JP, Zhang YX, Sun ZY, Fan QM \& Tian JW 2013 PPARgamma forms a bridge between DNA methylation and histone acetylation at the C/EBPalpha gene promoter to regulate the balance between osteogenesis and adipogenesis of bone marrow stromal cells. FEBS Journal 280 5801-5814. (https://doi.org/10.1111/ febs.12500)

Zhou H, Cooper MS \& Seibel MJ 2013 Endogenous glucocorticoids and bone. Bone Research 1 107-119. (https://doi.org/10.4248/BR201302001) https://joe.bioscientifica.com https://doi.org/10.1530/JOE-19-0230 (c) 2019 Society for Endocrinology Published by Bioscientifica Ltd. Printed in Great Britain
Received in final form 23 July 2019

Accepted 31 July 2019

Accepted Preprint published online 31 July 2019 